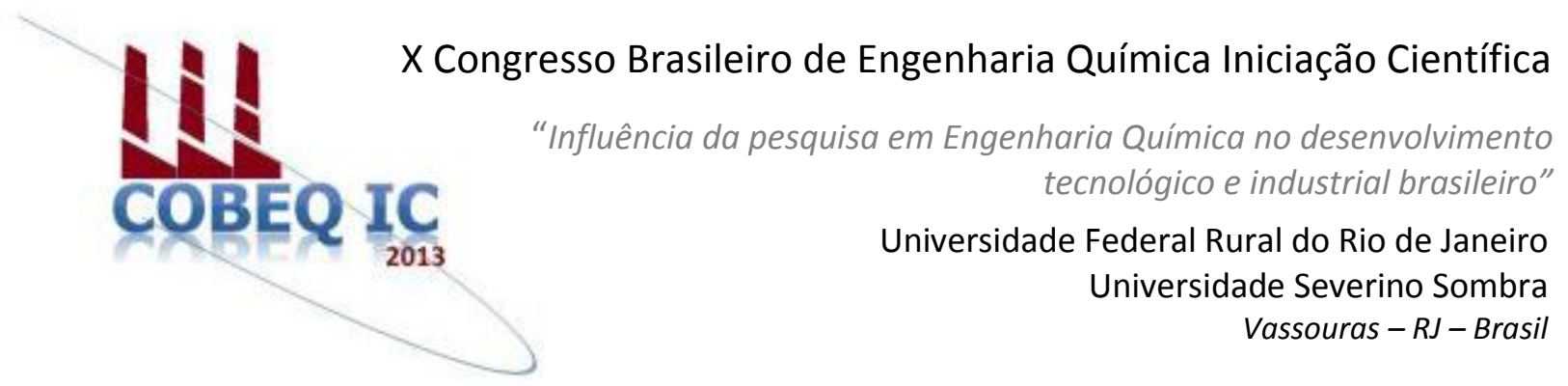

\title{
A INFLUÊNCIA DA LIGNINA NAS PROPRIEDADES REOLÓGICAS DA SOLUÇÃO DE VISCOSE
}

\author{
COSTA $^{1}$, D. V. B.; SILVA ${ }^{2}$, F. S.; CALADO ${ }^{3}$, V.M.A.; BARRETO ${ }^{4}$, D. \\ ${ }^{1}$ Aluno de iniciação científica ${ }^{2}$ Aluno de mestrado ${ }^{3}$ Professor do departamento \\ de engenharia química ${ }^{4}$ Professor do departamento de engenharia bioquímica \\ Universidade Federal do Rio de Janeiro,CT - Escola de Química - Bloco E. \\ Endereço-UFRJ, Av. Athos da Silveira Ramos 149 - CT, CEP. 21941- 909, RJ, \\ Email: fsouto@eq.ufrj.br
}

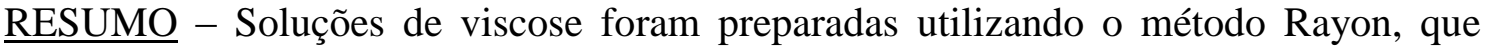
consiste na alcalinização da celulose, seguida de uma etapa de xantanização e posterior dissolução em soda cáustica. Foi estudada a influência da carga de lignina proveniente do bagaço de cana-de-açúcar nas propriedades reológicas dessas soluções. Foram utilizados dois reômetros rotacionais e diferentes geometrias para realizar os ensaios dinâmico e transiente da solução de viscose pura. Também foram efetuados ensaios estacionários da solução com e sem adição de lignina, tendo sido testadas diferentes proporções da mesma. Todos os ensaios foram realizados em temperatura ambiente, com uma frequência de rotação de $1 \mathrm{~Hz}$ e espaçamento de $1 \mathrm{~mm}$. Os resultados mostraram que a viscose pura apresenta a característica de um fluido pseudoplástico. A adição de lignina nas diferentes proporções preservou essa propriedade do fluido. Observou-se que a viscosidade aumentou consideravelmente com o aumento da concentração da lignina, fato esperado pela adição de carga à solução.
\end{abstract}

Palavras chave: celulose, xantato, Rayon.

\section{INTRODUÇÃO}

O processo de produção da solução de viscose é conhecido desde o final do século XIX. Esse processo foi inicialmente desenvolvido para a fabricação de fibras têxteis artificiais que fossem maleáveis, resistentes e com boa absorção de umidade ${ }^{[1]}$.

A fibra de viscose é uma fibra orgânica obtida a partir da regeneração de polímeros naturais, mais especificamente, da celulose. Essa regeneração se dá por meio de uma extrusão a úmido em banho de ácido sulfúrico, onde a celulose consegue se regenerar de forma lenta o suficiente para formar uma fibra que não seja porosa, resistente e flexível para ser enrolada em grandes carretéis ${ }^{[1]}$.

Uma limitação do processo de produção dessas fibras é obter uma celulose considerada pura para a fabricação da viscose. Para que isso aconteça, é necessário retirar demais substâncias comumente presentes em fibras vegetais.

Mesmo no algodão, fonte mais usada para obtenção de celulose nesse ramo da indústria por ter grande composição celulósica, 
existe uma parcela de material não celulósico, sendo um deles, a lignina ${ }^{[3]}$.

A lignina é um constituinte importante dessas fibras e está associada à celulose nas paredes celulares ${ }^{[4]}$. Dessa forma, é perceptível que a sua retirada é uma das etapas precedentes ao início da produção da solução de viscose.

Uma vez que a lignina e a celulose possuem uma forte interação ${ }^{[4]}$, é conveniente estudar a sua influência no processo. Com o objetivo de avaliar as propriedades reológicas da solução de viscose pura e analisar a influência da lignina nas mesmas, o presente estudo permitiu a análise de soluções puras de viscose por meio de diversos testes reológicos e uma primeira avaliação superficial da influência da lignina.

\section{MATERIAIS E MÉTODOS}

\section{Materiais}

Para a produção da solução de viscose, foram utilizados aproximadamente $1,5 \mathrm{~g}$ de algodão de marca comercial, $100 \mathrm{~mL}$ de uma solução de $\mathrm{NaOH}(16 \% \mathrm{~m} / \mathrm{v}), 30 \mathrm{~mL}$ de $\mathrm{CS}_{2}$, $15 \mathrm{~mL}$ de acetona e $4 \mathrm{~mL}$ de uma solução de $\mathrm{NaOH}(4 \% \mathrm{~m} / \mathrm{v})$. Todos os reagentes inorgânicos são da marca Sigma Aldrich, enquanto o algodão foi de um fabricante comercial, Apolo.

Cerca de 1,2 $\mathrm{g}$ de lignina foi utilizado no total, sendo proveniente do bagaço da cana-deaçúcar, subproduto do processo de obtenção de etanol de segunda geração, produzido nas dependências do Laboratório de Bioprocessos (LADEBIO) da Universidade Federal do Rio de Janeiro (UFRJ).

Os reômetros utilizados nos ensaios foram das marcas Physica, AR G2 e Haake. As geometrias foram cone-placa $\left(2^{\circ}\right.$ e $35 \mathrm{~mm}-$ Haake; e $1^{\circ}$ e $50 \mathrm{~mm}$ - Physica) e cross hatch (60 mm).

\section{Métodos}

Aproximadamente $1,5 \mathrm{~g}$ de algodão foi misturado em $100 \mathrm{~mL}$ da solução de $\mathrm{NaOH}$ $(16 \% \mathrm{~m} / \mathrm{v})$ e deixado sob agitação constante, em temperatura ambiente, por $4 \mathrm{~h}$. O material, filtrado a vácuo, e o algodão alcalinizado foram vertidos para $45 \mathrm{~mL}$ de uma mistura de $\mathrm{CS}_{2}$ e acetona (2:1). A reação durou cerca de 3 $\mathrm{h}$, sob agitação magnética. O material formado foi novamente filtrado, separando a fase líquida do xantato, que foi dissolvido em 40 $\mathrm{mL}$ de $\mathrm{NaOH} 4 \%(\mathrm{~m} / \mathrm{v})$, sob agitação, por uma noite.

Lignina foi acrescentada a $10 \mathrm{~mL}$ de solução de viscose, em duas diferentes proporções: 40:1 e 80:1, respectivamente.

Para todos os ensaios, o espaçamento foi de $1 \mathrm{~mm}$ e a frequência de rotação foi de $1 \mathrm{~Hz}$.

Para o ensaio estacionário, a taxa de cisalhamento foi de $0,01-100(1 / \mathrm{s})$ e o tempo de distribuição foi de 6 pontos por década.

Para o ensaio dinâmico, a varredura de tensão foi de 0,01-1000 (Pa) com tempo de distribuição de 6 pontos por década.

Para 0 ensaio transiente, a tensão cisalhante utilizada foi de $1 \mathrm{~Pa}$, em um tempo de $20.000 \mathrm{~s}$ com distribuição de 1 ponto por $\mathrm{s}$.

\section{RESULTADOS E DISCUSSÕES}

Após a realização do ensaio estacionário da solução de viscose pura, obteve-se o gráfico representado na Figura 1.

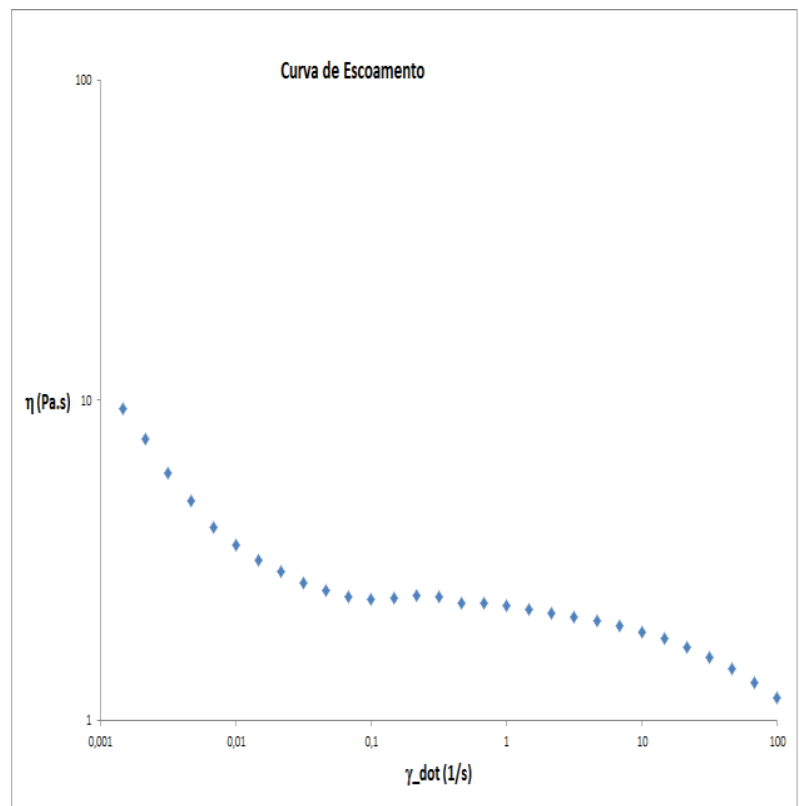

Figura 1 - Curva de escoamento.

É possível observar que, conforme a taxa de cisalhamento aumenta, a viscosidade da solução diminui. Esse comportamento é característico de fluidos pseudoplásticos.

Além disso, percebeu-se que o limite mínimo de torque confiável para a análise foi na taxa de $0,01 \mathrm{~Hz}$. Isso, porque abaixo dessa 
taxa, os resultados da triplicata ficaram oscilantes.

Com a adição da lignina nas duas diferentes proporções mencionadas anteriormente, obtiveram-se os resultados representados na Figura 2.

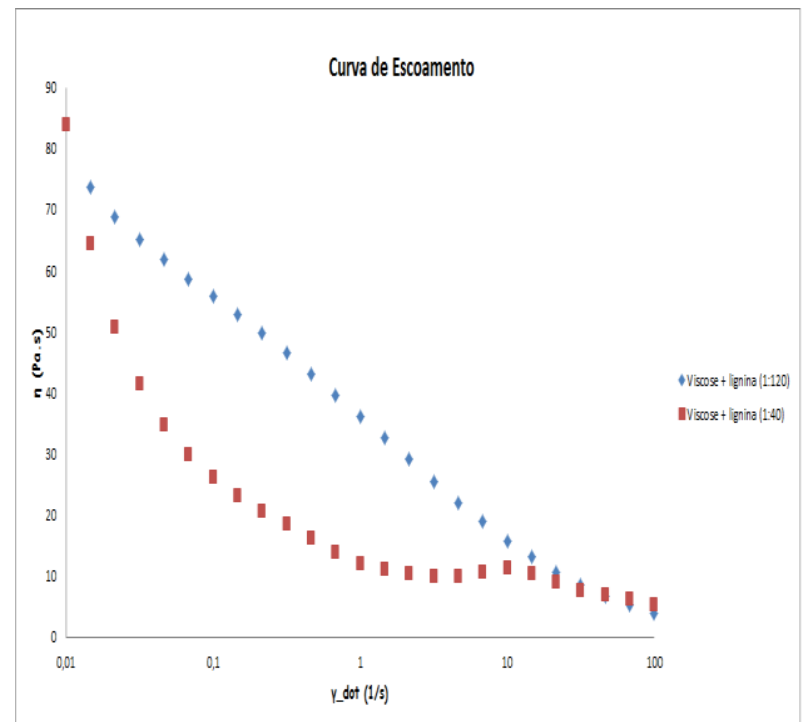

Figura 2 - Curva de escoamento.

Enquanto a viscosidade da lignina pura em baixas taxas de cisalhamento foi da ordem de 10 Pa.s, com a adição da lignina, a viscosidade praticamente aumentou em 8,5 vezes o seu valor, conservando um comportamento de fluido pseudoplástico.

$\mathrm{Na}$ Figura 3, está representado o resultado do ensaio dinâmico feito com a solução de viscose pura para os reômetros Haake e Physica, com as geometrias coneplaca e cross hatch.

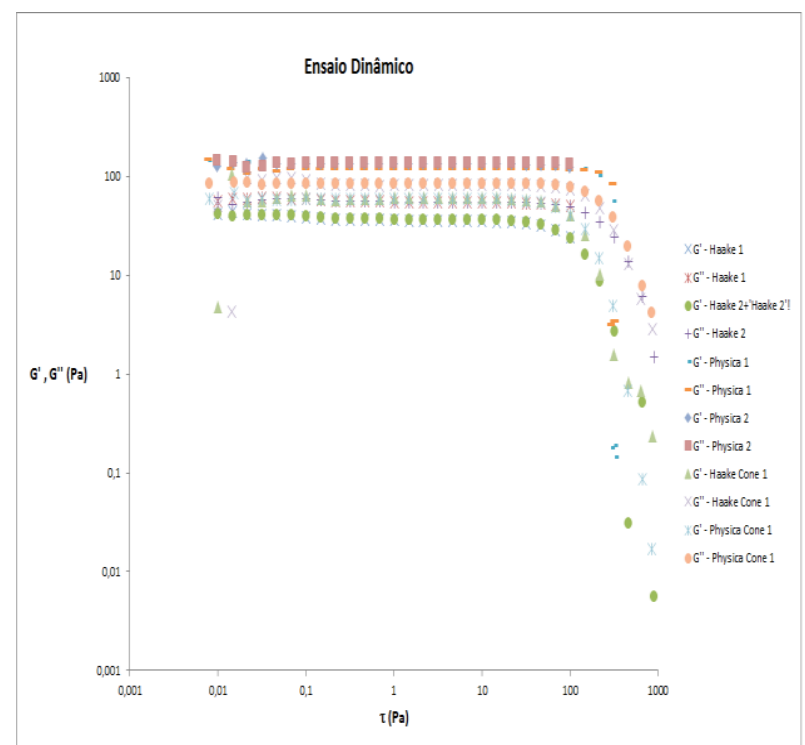

Figura 3 - Curva de ensaio dinâmico.
Analisando os resultados mostrados nessa figura, foi possível concluir que a geometria mais adequada para esse tipo de ensaio é a cone-placa, uma vez que somente para essa geometria os resultados foram uniformes e condizentes nos diferentes reômetros. Para facilitar a compreensão desses resultados, foram representados na Figura 4 apenas os pontos obtidos com essa geometria.

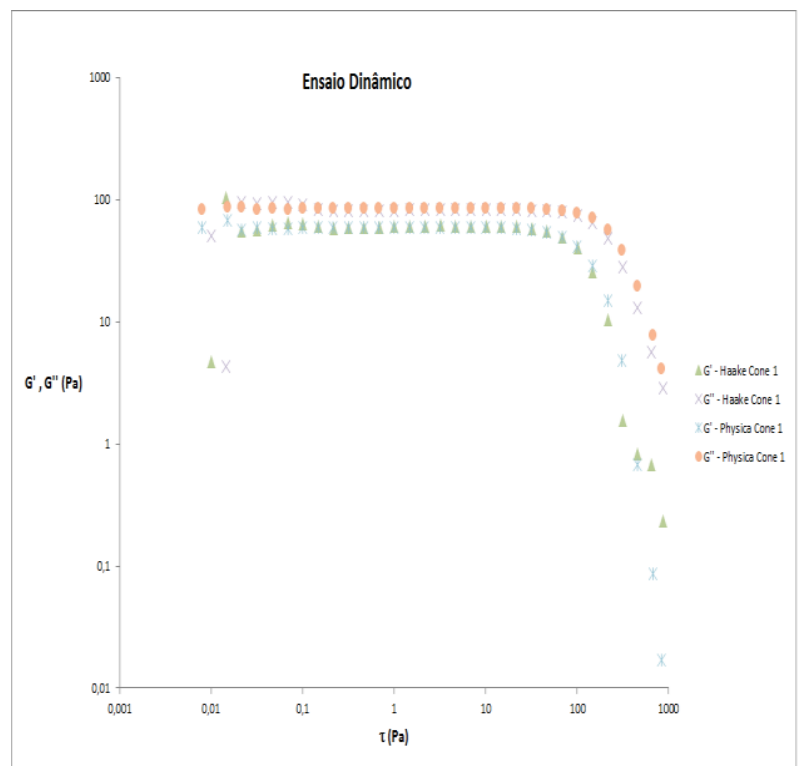

Figura 4 - Curva de ensaio dinâmico.

O ensaio dinâmico mostrou uma ampla faixa de viscoelasticidade linear, em que os módulos de perda e de armazenamento se mantêm constantes. A determinação dessa faixa é extremamente importante para garantir que o material utilizado não está sofrendo mudanças em suas propriedades. No caso da solução de viscose essa faixa foi de $10^{-2}-80$ $\mathrm{Pa}$.

Na Figura 5, é mostrada a curva proveniente do ensaio transiente, que permite avaliar se o fluido analisado varia suas propriedades reológicas com o tempo. 


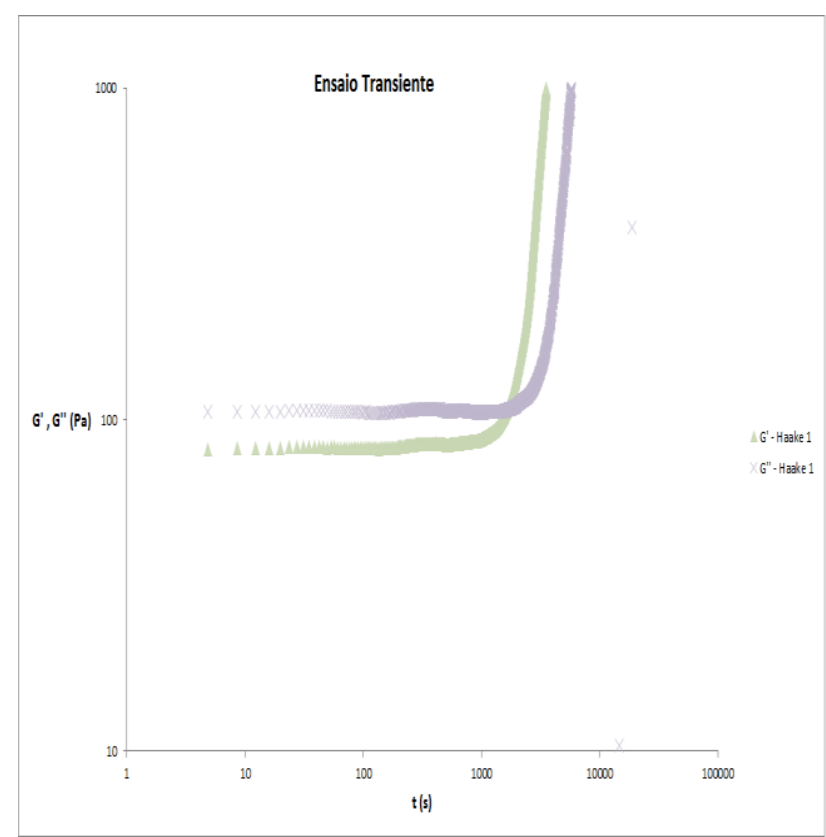

Figura 5 - Curva de ensaio transiente.

A curva do ensaio transiente mostrou que o fluido varia de forma considerável com o tempo. Na medida em que o tempo de ensaio aumenta, a viscosidade cresce exponencialmente. Com isso, o fluido é caracterizado também como sendo reopético ${ }^{[2]}$.

\section{CONCLUSÃO}

Os testes elaborados foram focados na solução pura de viscose, após se perceber que seu comportamento reológico é complexo o suficiente para exigir estudos detalhados. A avaliação da real influência da lignina nessa solução ainda carece de maiores apreciações.

Com os resultados obtidos no ensaio estacionário com a adição de lignina foi comprovado o que era esperado: ela aumenta a viscosidade da solução, mas o comportamento continuou pseudoplástico.

O estudo dinâmico apresentou uma ampla faixa da região de viscoelasticidade linear, independente da concentração da lignina, na proporção que foi estudada.

$\mathrm{O}$ ensaio dinâmico denotou que o fluido trabalhado apresentou um carater reopético, fato que dificulta a sua manipulação.

Com o aumento da viscosidade ao longo do tempo, o estudo desse fluido deve ser elaborado sempre considerando essa variável, ou seja, a elaboração das análises precisam ser efetuadas sempre em uma mesma faixa de tempo de manipulação, a fim de garantir a preservação das suas propriedades e poder comparar resultados sob as mesmas condições.

\section{NOMENCLATURA}

$\tau(\mathrm{Pa})$.................. Tensão de cisalhamento

$\eta$ (Pa.s) .................Viscosidade

$\gamma_{-} \operatorname{dot}(1 / \mathrm{s})$............Taxa de cisalhamento

G' $(\mathrm{Pa})$..................Módulo de perda

G” $(\mathrm{Pa})$...................Módulo de armazenamento

$\mathrm{t}(\mathrm{s})$ .Tempo

\section{REFERÊNCIAS}

1. BRINO, R. Ciência das fibras: Viscose. Faculdade de Tecnologia de Americana (FATEC-AM). Disponível em: <http://www.ebah.com.br/content/ABAA Ae09wAF/viscose > Acesso em: 22 de setembro de 2013.

2. EDISON, C. Fluidos Reopéticos e Tixotrópicos. Disponível em: <http://carlosedison.blogspot.com.br/2013 /04/fluidos-reopeticis-e-tixotropicos.html> Acesso em: 12 de novembro de 2013

3. NASCIMENTO, D. L., et al. Perfil

Lignocelulósico de Línter de Algodão. $34^{\mathrm{a}}$ Reunião Anual da Sociedade Brasileira de Química (SBQ)

4. SILVA, F. S. (2011), Projeto final de curso de graduação: "Aproveitamento da Lignina para Obtenção de Fibra de Carbono". Escola de Química, Universidade Federal do Rio de Janeiro, Rio de Janeiro.

\section{AGRADECIMENTOS}

Ao principal orientador, professor Felipe Souto, que sempre incentivou e apoiou o projeto, fornecendo as condições necessárias para a realização do mesmo.

À professora Verônica Calado, ao professor Nei Pereira Jr. e à equipe LABTeR. 